\title{
Unusual recurrent rectal carcinoma: A cancer field theory viewpoint
}

\author{
Kamil Vyslouzil ${ }^{a}$, Svetlana Brychtovab ${ }^{b}$ Pavel Zborila, Pavel Skalickya , Katherine Vomackovaa, \\ Michala Bezdekovab ${ }^{\mathrm{b}}$, Tomas Brychtac
}

\begin{abstract}
Aim. The rate of rectal cancer locoregional recurrence following radical surgery varies from $4 \%$ to $33 \%$. Though the causes are unclear, likely factors include microscopic tumor residues in the lymphatics, positive resection margins and exfoliation of tumor cells and their subsequent intraluminar spread during operation. Other significant factors include type and technique of surgical procedure. Recently, it has been demonstrated that local recurrence may also be associated with the biological behaviour of the tumor and/or with the composition of the cellular microenvironment which creates optimal conditions for the growth and spread of tumor cells.

Case report. The presented case here is interesting because the tumour recurred early following a curative surgical procedure with negative resection margins, without positive lymph nodes, without infiltration of the pelvic wall and without distant metastases.

Conclusion. In patients with a determined risk of genetically altered tumor field encompassing epithelial or stromal changes, a different treatment strategy, including gene therapy, anti-inflammatory or anti-angiogenic therapy should be chosen to minimize increased tumor risk.
\end{abstract}

Key words: rectal cancer, recurrence, cellular microenvironment

Received: February 16, 2012; Accepted with revision: September 14, 2012; Available online: November 2, 2012 http://dx.doi.org/10.5507/bp.2012.091

${ }^{a}$ Department of Surgery I, Faculty of Medicine and Dentistry, Palacky University Olomouc and University Hospital Olomouc, Czech Republic ${ }^{b}$ Department of Clinical and Molecular Pathology, Faculty of Medicine and Dentistry, Palacky University Olomouc

'Department of Recreology, Faculty of Physical Culture, Palacky University Olomouc

Corresponding author: Svetlana Brychtova, e-mail: Svetlana.Brychtova@seznam.cz

\section{INTRODUCTION}

The incidence of locoregional recurrence of rectal cancer in patients following radical surgery varies between $4-33 \%$ (ref. ${ }^{1-3}$ ). Approximately half of recurring carcinomas are localized in the true pelvis without the presence of distant metastases. Reasons for recurrence after a curative surgical procedure are unclear. A number of theories have been proposed with the aim of gaining a more thorough understanding of the conditions and causes for repeated recurrences. Among the most commonly described causes are microscopic tumor residues in the lymphatics, positive resection margins, tumor cell exfoliation and their subsequent intraluminar spread during operation, size of the tumor and its differentiation, age and sex of the patient. Other significant factors include type and technique of surgical procedure ${ }^{4,5}$.

The principle of surgical treatment of rectal cancer is radical removal of the segment containing the tumor, including total mesorectal excision. The radicality of the surgical procedure is a significant prognostic factor in the development of locoregional recurrence as well as patient survival. The long accepted rule of resecting the rectum $5.0 \mathrm{~cm}$ below the aboral edge of the tumor has been re-evaluated. In fact, extension of the rectal resection distally below the tumor is only possible in tumors of the upper rectum, where it may have oncological significance in cases of aggressive tumors with a high risk of metasta- sizing. Currently, it is accepted that a safe rectal resection requires parietal resection distanced $2.0 \mathrm{~cm}$ below the distal tumor margin ${ }^{6,7}$. However for tumors localized in the lower third of the rectum, in an effort to preserve the anal sphincter, a distal resection margin of $1.0 \mathrm{~cm}$ may be accepted $^{8}$, where the distance between the distal tumor margin and the resection margin is measured before it is immersed in the fixative solution. Extension of the procedure to the mesorectum is evaluated differently. In 10$20 \%$ of patients, tumor dissemination in the mesorectum may reach up to $4.0 \mathrm{~cm}$ below the distal margin of the tumor $^{9,10}$. Practically this means that only a mesorectal resection reaching $5.0 \mathrm{~cm}$ below the lower margin of the tumor is considered to be a sufficiently radical surgical procedure from an oncological viewpoint. While respecting that the distal resection margin in the rectum affects the development of local recurrence in the wall of the bowel, attaining radical excision of the mesorectum is a prognostic factor for locoregional tumor recurrence in perirectal tissues. It is important to remember that the tissue measurements are dependent on whether the material is native or fixed. Weese (1986) discovered, that preoperatively a $5.0 \mathrm{~cm}$ distance from the resection line after fixation of the specimen shortens to a distance of only $2.4 \mathrm{~cm}$ (ref. ${ }^{11}$ ), so the distance should be measured on the resected specimen before fixation in formaldehyde suspension. 


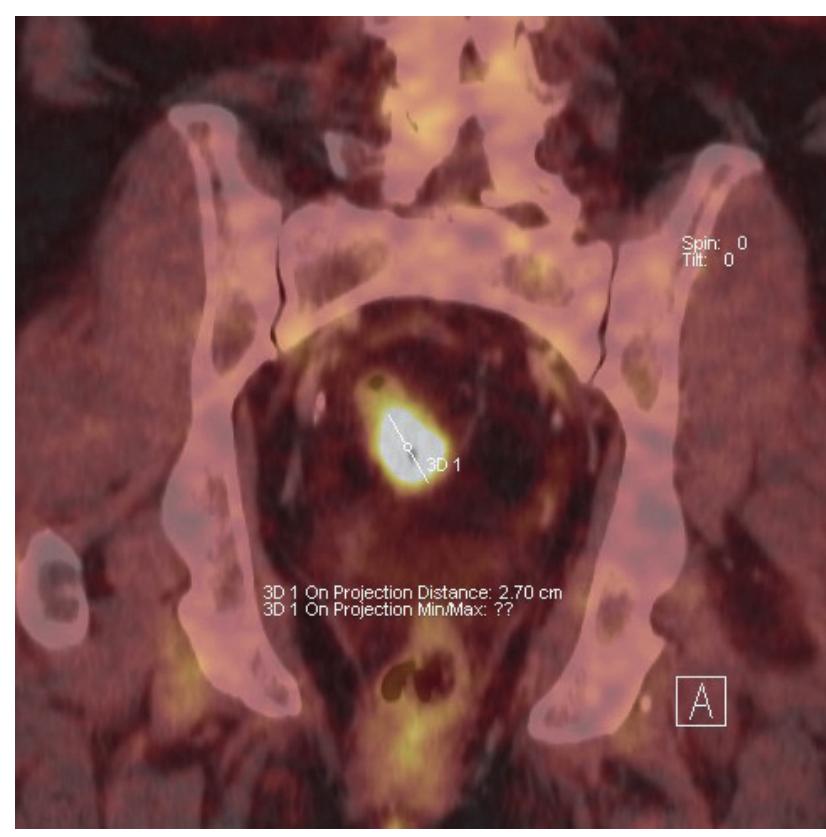

Fig. 1. PET CT 2007 - primary tumor. Increased 18F-FDG uptake in the thickened rectal wall, beginning $15 \mathrm{~cm}$ from the anal sphincter, width up to $14 \mathrm{~mm}$, length of $27 \mathrm{~mm}$, without signs of infiltration to surrounding structures. Pararectal lymph nodes without enlargement.

\section{MATERIAL AND METHODS}

A routine indirect immunohistochemistry was performed using primary anti $\mathrm{p} 53, \mathrm{CD} 3, \mathrm{CD} 4, \mathrm{CD} 8, \mathrm{CD} 34$, D240, nestin and EGFR (epidermal growth factor receptor). Examination for minimal residual disease using the method of reverse transcription and polymerase chain reaction in real time detecting carcinoembryonic antigen (CEA) and cytokeratin 20 (CK20) in samples of bone marrow, systemic blood and tumor tissue were performed.

\section{CASE HISTORY}

In 2007 a 66-year-old woman was operated for carcinoma of the rectum localized $15 \mathrm{~cm}$ from the anus. PET CT examination revealed increased 18F-FDG uptake in the thickened rectal wall without signs of infiltration into surrounding structures. Pararectal lymph nodes without enlargement (Fig. 1). Resection of the rectum was performed with radical excision of the mesorectum. To avoid the risk of incorporating viable exfoliated intraluminal cancer cell into the staple line, we performed rectal washout with $500 \mathrm{~mL}$ of saline. Pathological examination of the specimen revealed a tumor $40 \times 30 \mathrm{~mm}$ located $20 \mathrm{~mm}$ from the resection line. The tumor infiltrated the entire bowel wall and minimally extended into the perirectal fat to a distance of $0.2 \mathrm{~mm}$. The tumor was evaluated as intestinal adenocarcinoma G1, pT3N0MX. No progression via lymphatic vessels or blood capillaries was demonstrated. Both resection margins of the rectum were free of tumorous infiltration. A total of 12 lymph nodes were found in the mesorectum sized less than $10 \mathrm{~mm}$ with

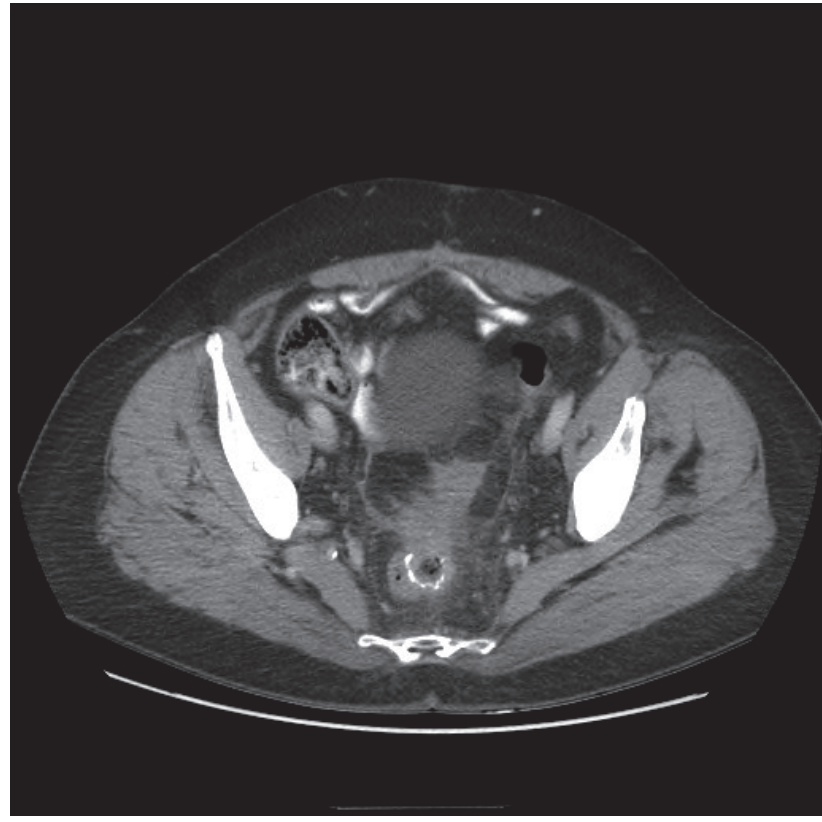

Fig. 2. CT 2008 - first recurrence. Local recurrence in the rectal anastomosis located $8-10 \mathrm{~cm}$ from the anal sphincter, irregular bowel wall thickening in the anastomosis, small lymph nodes in the vicinity. No signs of tumor invasion to surrounding structures.

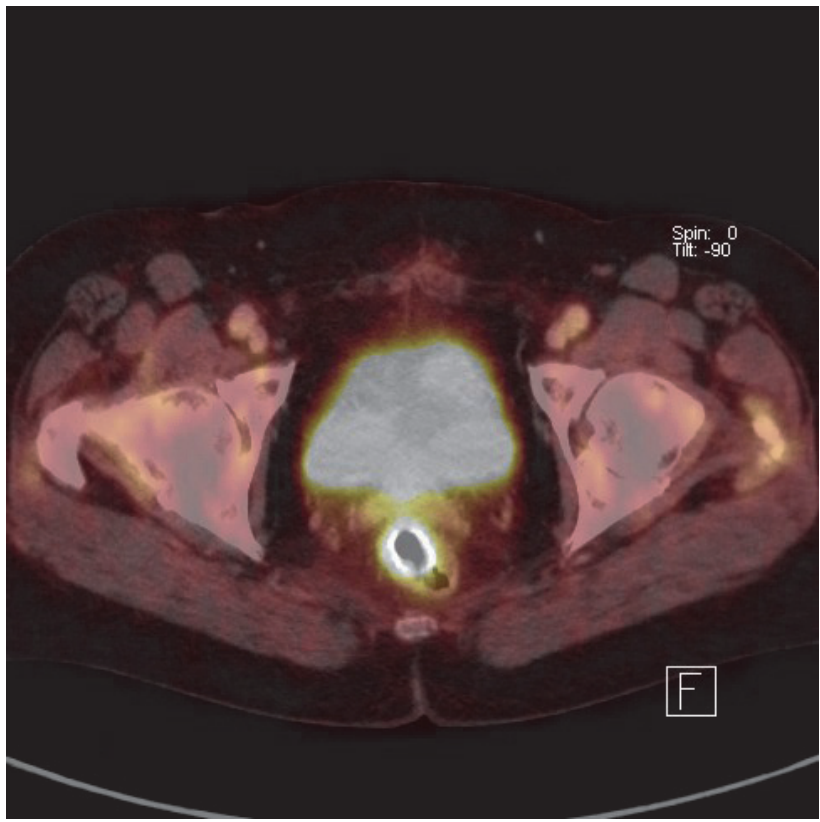

Fig. 3. PET CT 2009 - second recurrence. Findings of increased 18F-FDG uptake in the rectal anastomosis $4 \mathrm{~cm}$ from the anal sphincter with a length of $36 \mathrm{~mm}$, wall thickness up to $10 \mathrm{~mm}$. Without pathologically altered lymph nodes.

sinus histiocytosis and without signs of metastasis. The oncologist assessed the surgical procedure as sufficiently radical without the need for subsequent adjuvant oncological treatment.

During dispensarization 10 months following the first operation, an elevation of CEA was observed, and during endoscopic examination, local tumor recurrence was seen 
in the area of the colorectal anastomosis. CT showed no signs of disease dissemination outside the rectum (Fig.2). The patient was indicated for surgical re-resection of the rectum with low colorectal anastomosis. Pathological examination found tumorous infiltration measuring 40x17 $\mathrm{mm}$, located $22 \mathrm{~mm}$ from the aboral resection margin. Histologically, superficially ulcerated intestinal adenocarcinoma infiltrating the muscularis propria G1, pT2N0MX was detected. The resection margin of the specimen was free of signs of malignant cells. Eight lymph nodes without metastases were found in the mesorectum and mesocolon specimen. Postoperatively, the patient was treated with eight cycles of adjuvant chemotherapy consisting of Leucovorin and Fluorouracil according to DeGramont.

Six months after the last dose of adjuvant chemotherapy (11 months from the second rectal resection), a second local recurrence of adenocarcinoma was discovered in the anastomosis. PET CT showed no dissemination of the disease (Fig. 3). The patient underwent another surgical treatment, this time with abdominoperineal amputation of the rectum sec Miles. The pathologist described adenocarcinoma G2-3, pT3N0MX, infiltrating the entire wall as well as the perirectal adipose tissue. Two lymph nodes without tumorous infiltration were discovered. Furthermore, at a distance of $12 \mathrm{~mm}$ from the main tumorous lesion, a smaller focus of carcinoma localized in the submucosa was confirmed microscopically. After the operation for the second local recurrence, the oncologist indicated postoperative radiotherapy of the true pelvis and continual infusion chemotherapy consisting of fluorouracil for the patient.

\section{RESULTS}

None of the histological sections from the three surgeries showed invasion into blood or lymphatic vessels. The detection was done by immunohistochemical methods using monoclonal antibodies anti-CD34 and D240.

Cells from the primary tumor and recurrences showed strong diffuse expression of p53 and EGFR. Tumor cells were surrounded by desmoplastic stroma with numerous newly developed nestin-positive capillaries, increased number of tumor-infiltrating CD3+ lymphocytes, where CD4+ T helper lymphocytes predominated compared to the CD8+ subset. In the area of the tumorous stroma, nestin-positive cells were sporadically present in numbers of 1-2/1HPF (high power field). We examined surrounding as well as distant tissue sections of the bowel mucosa. No dysplastic changes were observed and inflammatory cellulization of the lamina propria were within normal range. Crypt cells were p53 negative throughout the entire sample, without overexpression of EGFR. In the stroma of the lamina propria, a few nestin-positive cellular elements were observed, especially in the second recurrence. Colonoscopically, no polyps were ever found in the higher bowel segments in our patient.

During surgery for the second tumor recurrence, tissue samples for minimal residual disease were taken. In a systemic blood sample, elevated expression of CK 20 was determined, which despite low expression of CEA attested to the presence of tumor cells and confirmed minimal residual disease. The bone marrow sample was negative. The second sample collection was taken one month following the operation, again confirming minimal residual disease, despite the decrease of CK20 expression in systemic blood.

The last follow-up was in June, 2011 with negative laboratory and computer tomography results. Subjectively the patient felt well.

\section{DISCUSSION}

This case is interesting as it demonstrates an early tumor recurrence. For this reason, a curative surgical procedure with negative resection margins was performed, without spread to the lymph nodes, without infiltrating the pelvic wall and without distant metastases. Despite fulfilling all requirements for oncosurgical radicality, two subsequent recurrences occurred. Both recurrences were local, referring to recurrences only in the rectal wall, not primarily locoregional, which develop in perirectal tissues and secondarily grow into the area of anastomosis. There are several possible explanations for this situation. We can exclude the possibility of incomplete surgical procedure, as resection margins were negative and radical mesorectal resection was performed. Local recurrences, which develop in the wall of the rectocolic anastomosis, could also originate from residual malignant cells of the primary tumor. Practically, this could be a result of intramural discontinual tumor spread which in our case is supported by the finding of an isolated tumor focus in the submucosa at the time of the second tumor recurrence. This type of tumor cell spread has been described in certain types of carcinomas, especially esophageal, gastric and rectal ${ }^{12,13}$. Liu et al. (2001) studied the extent of aboral intramural spread of rectal cancer in 98 patients and discovered intramural spreading distanced $0.1-2.5 \mathrm{~cm}$ in more than half of the patients (48/98), whereas of the total patient sample, only five patients exhibited tumor cells within the bowel wall beyond the border of $1.0 \mathrm{~cm}$ from the tumor. In $77 \%$, intramural spreading did not reach a distance of $0.5 \mathrm{~cm}$ from the tumor edge ${ }^{14}$. In our case, the resection was performed at a sufficient distance from the tumor, which is currently accepted to be at least $20 \mathrm{~mm}$.

Another fact, which should be considered, is the unfavorable phenotype of tumor cells. Overexpression of p53 is considered to be a negative prognostic marker, associated with more frequent locoregional recurrences ${ }^{15}$. In addition, overexpression of EGFR was discovered, whereas increased expression of the protein is considered a significant independent predictor of recurrence of rectal cancer ${ }^{16}$.

Another possible explanation is the theory of the tumor field, originally formulated by Slaugter ${ }^{17}$, where cumulating mutations of epithelial cells may be directly linked to either repeated local recurrences or with the development of multiple secondary primary tumors. Several lines of evidence indicate that the presence of a field le- 
sion with genetically altered cells is a distinct biological stage in epithelial carcinogenesis with important clinical implications. A field lesion has a monoclonal origin, and does not show invasive growth or metastatic behavior, the hallmark criteria of cancer. The theory of tumor field was further developed using molecular analyses and a number of genetic alterations in microscopically normal epithelium were discovered around the tumor focus, which gradually due to the process of multiple-step tumorigenesis transformed into tumorous epithelium ${ }^{18}$. One of the most commonly detected mutations within the tumor field is p53 mutation. Our patient, however, showed no overexpression of this protein in surrounding or distant crypt epithelium. Genetically altered isolated cells or groups of cells may migrate across the submucosa or via intraluminar spreading to reach more distant areas and thus create a basis for the formation of new tumor mass. Certain findings, for example in tumors of the esophagus and urinary bladder, support this theory. A field lesion may also have histological aberrations characteristic for dysplasia. In our case, no dysplastic changes were found in resected specimens. Currently discussed theories also include and emphasize the role of genetically altered stem cells, from which various cellular subclones may develop within the tumor field due to the gradual cumulation of mutations. Such cells basically are likened to "a time bomb", which lead to the development of malignant tumors.

Only recently acquired knowledge has led to the conclusions that the local tissue microenvironment contributes significantly to cancerogenesis and tumor progression. The tissue microenvironment is actually a result of extensive dynamic interactions between various cell types, and is an important factor in alterating tissue structure $^{19}$. Alteration of the stromal microenvironment including changes in the composition of the extracellular matrix with increased number of proteins such as fibrin, tenascin, fetal forms of fibronectin and abnormal proteoglycans, presence of inflammatory elements, and changes in protease activity, are important factors that support tumor growth and invasion ${ }^{20}$. Changes occurring in the tumorous tissue are linked to changes seen in granulation tissue created during tissue regeneration or changes seen in fetal tissue. One of the principal characteristics of tumorous stroma is neoangiogenesis, where nestin, an intermediate filament protein, and also expressed by stem and progenitor cells, is considered one of the main markers of angiogenesis ${ }^{21}$. Tumor cells regulate the development of tumor stroma by aberrant production of growth factors or induction of receptors for growth factors. The tumor stroma reciprocally affects differentiation and proliferation of tumor cells. As the surrounding stroma creates ideal conditions, a type of construction supporting the growth of the tumor, we assume that changes in the local tissue microenvironment around the anastomoses, mainly in association with the surgical procedure, contribute to repeated recurrences. Increase in the number of nestin positive capillaries, proliferation and activation of fibroblasts, rearrangement of extracellular matrix and the composition of inflammatory infiltrate create favorable conditions for recruitment, settling and subsequent proliferation of circulating tumor cells from minimal residual disease demonstrated in our patient.

\section{CONCLUSION}

In this unusual case, we examined various plausible explanations for the local cancer recurrence, where the described changes had significant practical consequences. A closer understanding of the mechanisms leading to tumor recurrence should lead to a better capture of at-risk patients and changes in therapeutic procedure. In patients with a determined risk of genetically altered tumor field encompassing epithelial or stromal changes, a different therapeutic strategy, including gene therapy, anti-inflammatory or anti-angiogenic therapies should be chosen to minimize increased tumor risk.

\section{ACKNOWLEDGEMENTS}

This work was supported by grant GACR P304/10/1070 from the Grant Agency of the Czech Republic.

Authorship contributions: TB, MB: literature search; SB, KVy: manuscript writing; SB, KVy, study design; PS, PZ KVo: data collection; MB, Kvo, PS, PZ: data analysis; $\mathrm{SB}, \mathrm{KVy}$ : data interpretation; $\mathrm{MB}$, TB,: final approval.

Conflict of interest statement: The authors stated that there are no conflicts of interest regarding the publication of this article.

\section{REFERENCES}

1. Slanetz CA. Effect of no touch isolation on survival and recurrence in curative resections for colorectal cancer. Ann Surg Oncol 1998;5:3908.

2. Bulow $S$, Moesgaard FA, Crone $P Q$. Recurrence and survival after conventional low anterior resection for rectal cancer. Ugeskr Laeger 2001;163:3793-7.

3. Ratto C, Ricci R, Rossi C. Mesorectal microfoci adversely affect the prognosis of patients with rectal cancer. Dis Colon Rectum 2002;45:733-42.

4. Bebenek M. Abdominosacral amputation of the rectum for low rectal cancers: ten years of experience. Ann Surg Oncol 2009;16:2211-7.

5. Radcliffe A.Can the results of anorectal (abdominoperineal) resection be improved: are circumferential resection margins too often positive? Colorectal Dis 2006;8:160-7.

6. Williams NS, Dixon MF, Johnston D. Reappraisal of the $5 \mathrm{~cm}$ rule of distal excision for carcinoma of the rectum. Br J Surg 1983;70:150-4.

7. Russell AH, Harris J, Rosenberg PJ, Sause WT, Fisher BJ, Hoffman JP, Kraybill WG, Byhardt RW. Anal sphincter conservation for patiens with adenocarcinoma of the distal rectum: long-term results of radiation therapy oncology group protokol 89-02. Int J Radiat Oncol Biol Phys 2000;46:313-22.

8. Shirouzu K, Isomoto $H$, Kakegawa T. Distal spread of rectal cancer and optimal distal margin of resection for sphincter-preserving surgery. Cancer 1995;76:388-92.

9. Scott N, Jackson P, Al-Jaberi T, Dixon MF, Quirke P, Finan PJ. Total mesorectal excision and local recurrence: a study of tumor spread in the mesorectum distal to rectal cancer. Br J Surg 1995;82:1031-3.

10. Ono C, Yoshinaga K, Enomoto M. Discontinuous rectal cancer spread 
in the mesorectum and the optimal distal clearence margin in situ. Dis Colon Rectum 2002;45:744-9.

11. Weese JL, O'Grady MG,Ottery FD. How long is the five centimeter margin? Surg Gynecol Obstet 1986;163:101-8.

12. Ikeda $Y$, Kurihara H, Niimi M, Kodaira S. Esophageal intramural spreading from an adenocarcinoma of the esophagogastric junction. Hepatogastroenterology 2004;51:1382-3.

13. Damianov N. Pathologic and anatomic preconditions for radical sphincter preserving operations in carcinoma of the medial and distal rektum. Khirurgiia (Sofiia) 2005;3:43-8.

14. Liu $H$, Wan D, Wu Q. Distal intramural spread of rectal cancer studied on large slices. Zhonghua Zhong Liu Za Zhi 2001;23:50-2.

15. Zaanan A, Cuilliere-Dartigues P, Guilloux A, Parc Y, Louvet C, de Gramont A, Tiret E, Dumont S, Gayet B, Validire P, Fléjou JF, Duval A, Praz F. Impact of $\mathrm{p} 53$ expression and microsatellite instability on stage III colon cancer disease-free survival in patients treated by 5 -fluorouracil and leucovorin with or without oxaliplatin. Ann Oncol 2010;21:772-80.

16. Azria D, Bibeau F, Barbier N, Zouhair A, Lemanski C, Rouanet $P$ Ychou $M$, Senesse $P$, Ozsahin $M$, Pèlegrin $A$, Dubois JB, Thèzenas
S. Prognostic impact of epidermal growth factor receptor (EGFR) expression on loco-regional recurrence after preoperative radiotherapy in rectal cancer. BMC Cancer 2005;5:62.

17. Slaughter DP, Southwick HW, Smejkal W. Field cancerization in oral stratified squamous epithelium; clinical implications of multicentric origin. Cancer 1953;6:963-8.

18. Braakhuis BJ, Tabor MP, Kummer JA, Leemans CR, Brakenhoff RH. A genetic explanation of Slaughter's concept of field cancerization: evidence and clinical implications. Cancer Res 2003;63:1727-30.

19. Mueller MM, Fusenig NE. Friends or foes - bipolar effects of the tumour stroma in cancer. Nat Rev Cancer 2004;4(11):839-49.

20. Vermeulen L, De Sousa E, Melo F, van der Heijden M, Cameron K, de Jong JH, Borovski T, Tuynman JB, Todaro M, Merz C, Rodermond H, Sprick MR, Kemper K, Richel DJ, Stassi G, Medema JP. Wnt activity defines colon cancer stem cells and is regulated by the microenvironment. Nat Cell Biol 2010;12:468-76.

21. Ishiwata T, Matsuda Y, Naito Z. Nestin in gastrointestinal and other cancers: effects on cells and tumor angiogenesis. World $J$ Gastroenterol 2011;17:409-18. 